\title{
"You Have to Accept the Pain": Body Callusing and Body Capital in Circus Aerialism
}

\author{
Kevin Walby \\ University of Winnipeg, Canada \\ Shawn Stuart \\ University of Winnipeg, Canada
}

DOI: https://doi.org/10.18778/1733-8077.17.4.01

\section{Keywords: \\ Circus Aerialism; \\ Body Capital; Risk; \\ Injury; Pain; Training; \\ Aging}

\begin{abstract}
Little sociological research has examined the work of circus aerialists. Drawing from interviews with 31 circus aerialists in Canada, we explore what aerialists say about their bodies. Circus aerialism is an intense form of physical work, and aerialists endure intense pain during training and performance. Engaging with sociologies of the body and injury, we examine how body capital is generated, maintained, and lost in the career of the aerialist, as well as how injury accelerates this process. Injury and "aging out" of the circus are prominent themes in what aerialists say about their bodies. Arguing that circus aerialism is an undervalued form of work in which risk accumulates in aerialist bodies, we explore how aerialist bodies provide tacit cues about how to avoid injury and when to consider retirement. In the conclusion, we explain how this work contributes to sociologies of the body and circus.
\end{abstract}

Kevin Walby is an Associate Professor of Criminal Justice at the University of Winnipeg. He is the co-author of Municipal Corporate Security in International Context, as well as A Criminology of Policing and Security Frontiers. He is the co-editor of Access to Information and Social Justice: Critical Research Strategies for Journalists, Scholars and Activists; Brokering Access: Power, Politics and Freedom of Information Process in Canada; The Handbook of Prison Tourism; Corporatizing Canada: Making Business Out of Public Service; National Security, Surveillance, and Terror: Canada and Australia in Comparative Perspective; Policing Cities: Urban Securitization and Regulation in a 21st Century World; Corporate Security in the 21st Century:
Theory and Practice in International Perspective; and Emotions Matter: A Relational Approach to Emotions. He is the co-editor of the Journal of Prisoners on Prisons.

email address: k.walby@uwinnipeg.ca

Shawn Stuart holds a Master of Science in Criminal Justice from the University of Oklahoma. She has broad research interests in social identity and social control. Her primary research interest is in understanding belonging and how it is impacted by social exclusion, as well as how belonging shapes our relationships, social groups, and cognitive processes.

email address: Shawn.Stuart@alumni.ou.edu 


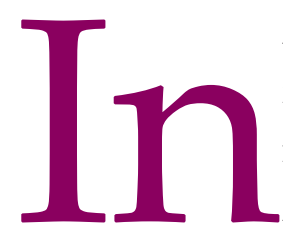

2018, circus aerialist Yann Arnaud fell to his death while performing for Cirque du Soleil in Tampa. A few years earlier, in 2013, aerialist Sarah Guyard-Guillot died from the result of a fall at a Cirque du Soleil show at the MGM Grand Hotel in Las Vegas. Aerialist Oleksandr Zhurov also died at a Cirque du Soleil training facility in Montreal in 2009. Part of what audiences have always found appealing about the circus is the way the performers appear to be in peril (Stoddart 2000), yet, little research has focused on the dangers of circus aerialism. A 2012 survey of the Ka show at which Guyard-Guillot died found that 56 out of 100 aerialists had experienced injury-a rate that is four times higher than professional sports and five times higher than firefighting (Berzon and Maremont 2015). As such, it is important to understand the risks to the bodies and lives of aerialists.

Circus aerialism is similar to high-performance sports in terms of risks and injury, yet it differs as it is set in an artistic context. As a performance art, aerialism combines aerial technique and dance by working with silks, hoops, ropes, and trapezes to suspend the aerialist's body midair. The body, having the freedom to float, can twist and turn itself into a visually appealing dance. This graceful display, performed individually or with partners, is fascinating given that the aerialist's body is contorting into painful positions. The shocks absorbed by the aerialists' bodies flying high above crowds would rupture most humans. Still, circus aerialists captivate their audiences with theatrical performances and death-defying maneuvers. Such performances are the product of intense training and choreography that prepares and engages the aerialist's body and mind. Despite how fantastical circus performances appear to the audience, there is a need to explore the impact aerialism has on the bodies of performers.

We aim to understand the corporeal dimensions and physical culture of work (Giardina and Donnelly 2017). To do so, we draw from interviews with 31 Canadian circus aerialists to analyze their body talk (Oleschuk and Vallianatos 2019). While Rantisi and Leslie (2015) note that aerialism is creative work, we focus on the physical toll enabling those creative performances. Similar to Tynan and McEvilly's (2017) interview findings with retired elite gymnasts, our respondents articulate a desire to work through the pain and fear of injury for the love of their craft. Aerialism is a form of physicality and artistry that entails intense training and pain. Aerialists describe having to accept and adapt to physical pain. We analyze this tacit corporeal knowledge aerialists develop over time. Allen-Collinson, Crust, and Swann (2018) point to the need for more research on mind and body activities that are not divisible in practice. Circus aerialism is one of these types of practices and work.

The intensity of circus aerialism also leads to injury and "aging out" of the circus, both of which are prominent themes in what aerialists say about their bodies and work. We engage with sociologies of the body and injury to interpret these narratives, specifically, literature on body capital (Wacquant 1995) and body callusing (Spencer 2009). We show that aerialists must accumulate body capital, which entails body callusing and exposes aerialists to injuries and physical risks. We argue that aerialism is an undervalued form of work in which risk accumulates in the bodies of aerialists and that their bodies provide tacit cues about how to avoid injury and about when the body can no longer endure the trials of aerialism. 
First, we examine sociological literature on circus, bodies, and embodiment. Second, we offer a note on research methods. Third, we analyze interviews with 31 circus aerialists. Fourth, we focus on narratives about training, pain, risk, injury, and aging out that demonstrate how aerialists conduct body work and risky work. We examine how body capital is generated, maintained, and lost in the career of the aerialist and how the role of injury acerbates and accelerates this process. In the conclusion, we explain how this research contributes to sociologies of the body and circus.

\section{Literature Review}

\section{Performing Circus}

Truzzi (1968) wrote of the decline of the circus as a social institution. This was before the rise of the new circus. The family circus focused on the foreign, oddities, and animals, juxtaposing these against family as the cornerstone of the story and performance (Davis 2002). The family circus was also a social system with a strict hierarchy and assigned roles and performances based on race and gender (Easto and Truzzi 1973). New circus no longer relies on the same trope of family and now engages with more diverse storylines and forms of identity (Albrecht 1995; Carmeli 2003; 2007). Stephens (2019) notes that new circus aerialism is a collective practice. Circus also creates social and physical bonds among aerialists. As such, it is important to examine the issue of identity in the circus (Little 1995), but equally vital to assess the corporeal dimensions of aerialism.

Aerialists work for large and small companies, or independently when contracted for corporate events. Working for large companies can sometimes mean long-term contracts with employee benefits, where- as small companies or corporate events usually offer brief contracts with more costs and economic risks. In some cases, aerialists go months without paid work due to injury or lack of opportunity. Despite this, aerialists often have prolonged training schedules; the advantage of copious training is that the troupe learns to trust one another, which is crucial during performances. Regardless of the size of the company the aerialist works for, circus aerialism engulfs their identity.

One important facet of circus work we cannot explore fully here is the potential for breaking down traditional gender norms at work. Tait (2005) examines the gendered dimensions of circus bodies and aerialism. While upper body muscularity is conventionally associated with men, it is evident across genders in circus aerialism. As Tait (2005:3) suggests, "male bodies in graceful flight displayed qualities contradicting manliness, and muscular women went completely against prevailing social patterns of bodily restraint." The pursuit of muscularity and body power by women was re-legitimated at the beginning of the $21^{\text {st }}$ century, although there are still many representations of gender in the contemporary circus that reproduce gender stereotypes as well.

Pleasing a circus audience entails a projection of excitement and delight (Carmeli 1996). Although sports can elicit commotion among their audience, sports set the athletic body into direct competition with other athlete bodies and subjects them to measurement and scoring. In the circus, the body is not subject to scoring systems, rather the audience judges the body on its ability to allure. While gymnastics has rules and competition, there is a perception of the circus body "as oscillating between control and loss of control in a constant shift between the con- 
dition of playing and being played" (Tait 2005:261). The circus designs the story to display the aerialist in peril: "The design of the whole circus act-its early mimetic part, the balancing postures, the progress of the act towards 'more dangerous' routines, its closure by a 'final' feat-all intensified and explicated this process" (Tait 2005:262). Danger as a metaphor crystallizes the circus experience. As Willy, a circus artist, says: "they are after my blood" (Tait 2005:264). The risks are real, as we explore by considering what aerialists say about corporeality, injury, and aging.

\section{Body Work and Body Capital}

As Hockey and Allen-Collinson (2017) note, experienced athletes have an advanced sense perception of their bodies and injuries. An aerialist can feel if their rigging equipment is suitably tense or tight and their body part is too hot or sweaty for the next maneuver. As the aerialist is alert to the danger, they quickly calculate potential injury to adjust the body with the equipment. Through this haptic perception, the body unifies with the equipment, like a musician with an instrument. This union not only helps aerialists avoid injury but also express themselves. Developing this corporeal knowledge, the aerialist uses the body as a device for creative expression to bring excitement to audiences.

The sporting body is an antidote to the monotony and drudgery of modernity (Shilling 2005). Still, many forms of thrill-seeking are forms of work that adversely affect the body. During training, the aerialist endures intense pain and flirts with injury. To transform physically and mentally, aerialists embrace and "listen" to their bodies for injury. Staying aware of physical stress and tension is important since injury creates a disrupted body (Allen-Col- linson 2017) that can no longer function at an elevated level in a sport or thrill-seeking activity. One can also experience body disruption as a dissolving of the self or a breakdown of identity (also see Sparkes and Smith 2002). As such, we focus on injury as it manifests in training, performances, and retirement in aerialism.

Given the work on the self and touching of other aerialists, circus aerialism is a form of body work (Wolkowitz 2002). It entails working on one's body, but also manipulating the bodies of fellow aerialists. Wolkowitz (2006) argues that the sociology of work has ignored bodies. Specifically, scholars have singled out the bodies of manual laborers instead of the bodies of artistic workers. The reasoning behind the limited research on artistic workers could be due to the ample number of manual laborers compared to artistic workers or the ease of access to studying a more available group. In addition, fewer researchers may have access to gatekeepers or key informants involved in circus work.

Aerialism also involves the accumulation of body capital. There are forms of body work that entail the accumulation of forms of "body capital" (Wacquant 1995) or physical capital (Bourdieu 1978), which are specific to a set of situated practices. Wacquant (2004) sees the body as having somatic potentialities that can become valued. When Wacquant (2004) discusses the assembling of body capital, he states the objective is to build body capital without extinguishing it through training. Although some body capital is primarily aesthetic (Frew and McGillivray 2005; Hutson 2013), some body capital is cherished only for its use value or the corporeal and technical skill this body capital facilitates. The goal is to peak with body capital during the performance. The same author assumes that the body worker needs to 
build capital through repetitive episodes of training (Wacquant 1995). Body callusing (Spencer 2009) is the process by which an individual builds physical capital. The repeated training fortifies the aerialist body and transfers skills among corporeal experts in training centers. As the body calluses, it assists the body in accepting pain. Undergoing this pain creates a form of identity and membership for circus aerialists (cf. Spencer 2009; Rafalovich 2016). Over time, however, injuries and aging erode this bodily capital. Researchers in many disciplines have a keen interest in body callusing as it relates to injury. Understanding body callusing is crucial to understand because it provides insights into the injurious elements of work. Below we examine how body capital accumulates and declines in aerialism.

\section{Research Design}

While we do not offer an ethnography of circus aerialism, following Allen-Collinson and colleagues (2018) our research design and analysis provide a phenomenologically oriented sociology. Such an approach entails focusing on the sensual and situatedness of both consciousness and action in the body (Allen-Collinson and Hockey 2011). Ingold (2000) argues it requires focusing on concrete descriptions of actions, thinking about the specific in relation to the whole, and the analysis of articulated experiences.

The first author interviewed 31 circus aerialists, ranging in age from 22 to 37.12 circus aerialists identified as men and 19 aerialists identified as women. Many aerialists had secondary work as yoga teachers, bartenders, or aerialism coaches. A few aerialists owned small circus schools or small circus companies. We contacted initial interviewees through the distribution of posters in Montreal and Ottawa. Respondents contacted the first author if they wished to participate in the study. Interviews occurred in coffee shops or homes of the respondents, whatever made them feel most comfortable (Nespor 2000). Interviews were flexible, but based on a thematic interview guide. The guide included questions about their experiences of the body and risk. We further asked questions about their history of circus work, circus injuries, and retirement. The first author also conducted observations at a circus school in New York City. We acknowledge that an autoethnographic approach would provide even more detailed data on the corporeal dimensions of circus aerialism and the sensations and pain aerialists endure.

The first author conducted interviews and initially coded interview data for (1) narratives concerning the body and work, and (2) work risks. The interviews were emotionally intense at times, and some aerialists wept when reflecting on pain and injury, which speaks to the physical and mental toll of this work (see: Corbin and Morse 2003). However, participants did not oppose speaking about the injury. The authors worked together during data analysis to ensure rigor and credibility during the selection and interpretation of interview excerpts (Tracy 2010). We substituted pseudonyms for respondents' names if they opted to select one.

\section{Aerialism and the Body}

\section{“...the hands will have calluses": Training and Pain}

For the aerialist, the body must become a sort of Swiss army knife (Van Lenning 2004) that they can manipulate to achieve incredible feats. To manipulate the body into acrobatic maneuvers, the aerialists undergo continuous and intensive training. Through this training, aerialists become acutely 
aware of when they sharpen and dull their corporeal senses and skills. The training to create this instrument is grueling, but during training the aerialists establish an intimate knowledge and relationship with their bodies.

For doing aerial work, the biggest challenge is training, is building for strength and grip strength to be able to hold yourself up for six minutes. [Circus_02, woman]

...through this great awareness of my body, I eventually overcome chronic fatigue and chronic injury situations...through my acrobatic training, I learned more about the muscles and the engagements that were necessary to keep good alignment...I feel a deeper, emotional relationship with my body. [Circus_18, man]

...it's a lot of conditioning just to get enough muscle to do the tricks, whereas hoop diving, the Chinese hoop diving is more of a precision thing...it's more of really concentrating in and trying to find the center, and if you have too much adrenaline, you jump too high and you have to control, it's a lot more control. [Circus_09, man]

The body is an accumulated history of the movement that alters its materiality (e.g., toughness of the hands and feet) depending on the practice. Physical capital (flexibility, speed, tough skin, stamina) is built through training and work on the self. To accumulate body capital, habituated and focused action must be undertaken (Shilling 2004). To develop strength and precision, the aerialist engages in training regimes in which the body becomes conditioned and endures pain. Part of the training is for the body to be taught how to endure pain. This echoes Encandela's (1997) findings on aging and pain among individuals in a retirement community. The author found that, in some cases, individuals were encouraged to focus on things other than pain, such as group activity, as giving into the pain would lead to bodily decline and defeat.

It takes years...it's really painful when you miss your tricks...pole is tough on the body, you get lots of burns...it's a lot of conditioning just to get enough muscle to do the tricks. [Circus_09, man]

Trapeze is painful...the metal bar on your skin is painful, the ropes are painful. You have to develop the strength, but it's not the hardest, everybody can develop strength. The hardest in the aerial area is to get used to the pain...it's like your skin or your body adapts to this pain, to this hurt, to this shock. This is incredible to see how your body can adapt, the hands will adapt, the hands will have calluses. [Circus 01, woman]

Aerialists undergo a bodily transformation where they gain physical control over the body. The control not only permits them to endure the pain but also to manage the fear that comes with the risk of injury and flying high above the audience. While the aerialists agreed that the hardest part of aerialism is the pain, it could be that proving oneself or remaining competitive motivates the aerialists to deal with the pain. Eventually, an experienced aerialist develops a high pain tolerance (cf. Rafalovich 2016). As one aerialist notes, "You have to accept the pain and go for the pain, do it every day, and you have to like it" [Circus_01, woman]. In engaging the transformation of their bodies and the physical capital of an aerialist body, the performers push personal boundaries.

You finally get used to the pain, even your bruises. You're going to do a move, and you're going to have 
bruises with a new move for maybe one or two months. You're going to have a bruise, and then, at some point, your bruises will disappear... [Circus_01, woman]

There was a time when I broke my finger and I didn't even know...I didn't even remember anything going wrong in the piece. [Circus_19, woman]

These forms of repetition and intense training comprise body reflexive practices. Body reflexive practices are repetitive actions undertaken to prepare the body for skilled performance (Crossley 2005). Body reflexive techniques that generate a toughening of the body, especially those meant to overcome pain, entail body callusing (Spencer 2009). Body callusing is building toughness and endurance to "withstand the rigors" (Spencer 2009:133) of an athletic activity, which results in the embodiment of strategy. Training and performance develop body capital that makes the performer an asset to an organization (Shilling 2017). Further, the aerialist only deploys the use value of body capital in the context of the performance.

\section{“They wouldn't let her do any pull-ups...": Body Image}

As with other high-performance athletes such as rowers (Chapman 1997), aerialists must work on their bodies to make them perform. Body image may even be a secondary issue compared to performance and capability. Aerialists describe the need for strength and ability over the appearance of the body to perform maneuvers. In some cases, aerialists describe a woman's "masculine" strength as a highlight in a performance.

I used to do an act with a guy where we'd do balancing on each other, and one holds the other person, and normally the man holds the woman, right, but since I'm a bigger, stronger woman, we shared the role, which was our selling point. [Circus_03, woman]

If you want to work in the circus, you need to take good care of your body. We're running solid for 2 hours, you're on stage, or you're doing something backstage, or you're stretching. You need to be in top shape and that's your job as a circus performer, to keep your body in really good condition. It doesn't necessarily need to be ridiculously skinny or extraordinarily muscular, but it does need to be fit. [Circus_02, woman]

The aerialist must develop a rare physical skill set that would amaze even other high-performance athletes and thrill-seekers. At the same time, it could be argued that aerialists are more concerned with body image compared to other athletes, especially since their bodies are decoratively on display. The aesthetic feature of the body (Vannini and McCright 2004) in aerialism could also contribute to body capital development. This "body talk" (Oleschuk and Vallianatos 2019) reveals how aerialists think of the results of body reflexive practices, but also pressures put on them by their employers. Based on pressure from circus companies, there is an expectation for some women aerialists to maintain femininity. Traditional gender performances remain part of some circus plots. This gender expectation demonstrates traditional gender-streaming in the new circus. There is an expectation for women aerialists to weigh on the lighter side. Such expectations may lead the aerialist to unhealthy eating habits to maintain a particular body image. Dieting to achieve a self-governed body shape (Turner 1982) is common. Body expectations among circus companies also dictate how often an aerialist might work. Therefore, aerialists toughen the body to en- 
able them to endure pain, but they may also undertake practices to maintain the expected body image.

They wouldn't let her do any pull-ups. They wouldn't let her do any conditioning that was muscle building. They didn't want her to be muscle-y...I know tons of people that don't eat, or they starve themselves and they do way too much cardio. [Circus_03, woman]

At Cirque Éloize the style is very European. The director wants women to look like women, so he encourages you to have the body that is most naturally yours... with the exception of me, all the other girls have long hair and we wear dresses so a more feminine body, if you have hips and you have breasts, that's OK....it is easier to lift yourself on the fabric if you're lighter. [Circus_02, woman]

At Cirque du Soleil they have written in your contract that you have to maintain a certain amount of weight...directors will pressure you depending upon your role in the circus to maintain a certain body image...it's also inherent a lot in the circus schools because they'll say, "If you want to be a circus artist, you're going to have to lose 10 pounds"...anorexia and eating disorders are rampant... [Circus_05, man]

On the other hand, we observe the aerialists equating body scars with positive imagery, which is contrary to positive body imagery assuming that body scars are equated with negative imagery. To the aerialist, bodies scarred through training or injury represent achievement and expertise. Even though an aerialist described being more attractive without scars, the aerialist is the aerialist is proud and amazed at how they obtained their scars.

Everyone feels more attractive if they don't have scars and everything, but in a way, I'm glad that my scar has a cool story because people like that story. [Circus_19, woman]

Aerialists even describe the body as appearing robust and transcendent during an accident that led to injuries and scars. The aerialists may be shaken by accidents and, at the same time, amazed at the sight of the injured body rather than unsettled by its marred appearance. While the aerialist describes a comfort in feeling attractive, she proudly describes the accident in which she now carries a symbolically important scar. She even ends the story by suggesting the moral of the story is to back up your shackles, almost nonchalant, indicating the importance of fortitude before aesthetics.

There was a shackle that attaches the platform attached to the crane bar and...the shackle hopped and I fell...I grabbed onto the bungee cord that the trapeze was hooked by and I was able to delay my fall a little bit by holding that bungee until the bungee snapped. When it snapped, I got torqued the other way...I twisted and caught it in my elbow and you can see the scaring...I'm riding down it just trying to hold myself as my skin is coming off and I can see that I'm coming to the edge of the net and I'm not going to be able to land in the net. So I flung myself off it and tried to twist so I could get to the net...It was like a 24-foot fall and I had bad burns...So the moral of the story is back up your shackles... [Circus_19, woman]

If you look at pictures from after that, because someone took a picture of me right after I fell, and the picture looks 3D. I feel like I was so vividly alive and shaken at that moment that it's coming out through the photo, my muscle looks like it's popping out of my skin and my veins look like they're popping out of my skin, I look like an Olympic athlete just because I think I was so pumped with adrenaline about the 
fall...I probably wouldn't fly again if I could actually see what happened. [Circus_19, woman]

One can view the scar as a form of perseverance in a regime of body reflexive practices that are demanding and grueling in many ways. The stories about scars and accidents can also be interpreted as viewing the body with fascination and amazement with what it endures and how it adapts. The aerialist body must have some aesthetic appeal, but it is much more important it be a functional tool for performance.

\section{Performance: Putting Body Capital to Work}

Aerialists describe the body as a separate entity that they manipulate to experience transcendence. In a sense, aerialism is an escape from contemporary life. Some aerialists speak of their bodies metaphorically, as a vessel that can tell stories (also see Oleschuk and Vallianatos 2019). Circus aerialists also mention that an element of escape is integral to their circus performances. This masterful dissociation assists aerialists in overcoming the fear of heights, potential injury, and pain.

I see myself more as a vessel of storytelling....and it's a process of living between the extremes consistently. The pain and the exhilaration and just doing it every day. That continuum, that's what I think has made it a very emotional, an emotionalized process for me, and with my body being more than just a simple physical device. [Circus_18, man]

Up there, you have to be in your own world...you have to create a small space because if you start to think about how high you are, how many people are watching you, you can panic...You have to have this ability to be happy in the air...you feel that you're alone in the world...You feel very special. You know that everybody is watching you, but it's not you, it's somebody else. It's like a dream. [Circus_01, woman]

The connection of the body to the aerial apparatus is synchronistic (Shilling 2005; Austin 2009; Byczkowska-Owczarek 2020). The aerialist feels physically and emotionally connected to the apparatus (also see Coetzee 2020; Rau 2020). A unification occurs between the aerialist and the apparatus. One can also interpret a merger between the aerialist and the story. These kinds of embodied subjectivities form in specific spaces and respond to routines and physical practices.

My body is everything on the trapeze. The way I do trapeze, there's not much difference between the apparatus and myself. We're always connected unless I've left it. It goes beyond just holding on, it goes more to the tension that's in the ropes is also in my arms and the rigidity is in my feet or in my shoulder, or you share the roles that each piece of the apparatus takes, or each piece of my body takes the apparatus has to adapt. If I want to twist with my body, I have to twist with the ropes. [Circus_03, woman]

The body is one of the main repositories of those stories and the way that we understand them. The gestures, the simple gestures of flight and aerialism, it's something that is so universal that you don't even need to understand how to speak to get it...I've learned it from other people and brought the ideas from other places, and it translated through my body and translated into other people, and I think the organization is sort of the ultimate manifestation of that here. [Circus_18, man]

The aerialist views their profession as a means for expressing passion through the body. Like profes- 
sional wrestlers (Corteen 2019), circus aerialists often work through the pain that would overwhelm the average human. No matter the pain, the aerialist must display a body that is in accord with the theme of the show rather than a body that is suffering.

\section{"...my teeth had been pushed up into my skull": Aerialism and Risk}

Athletic performance is risky work since it is not often compensated well except at the elite level. Yet, the risk of injury is downloaded onto the performers while the organizations benefit financially (Roderick, Smith, and Potrac 2017). Aerialists use the idea of risk as a trope to tell stories about their bodies' work. There is considerable risk in aerialism, including financial, gendered, physical, and emotional. Circus workers are precarious workers (Stephens 2015). They experience economic precarity, as well as other forms of risk since circus companies offer limited contracts and few benefits. ${ }^{1}$ The physical risks are equally serious and can have dire consequences.

While both the aerialists and rigger workers (who set up the equipment) conduct safety checks of their equipment, the risk of physical injury is always present.

I woke up, I was lying on the ground...the most intense pain was in my hands, but also in my teeth...I did see my arms, I had compound fractures on both sides with the right side bearing the brunt of the fractures. My bones were like dust, the end of the bones were into 100 pieces on the right side. The left side was freakier as a large gash of bone came through the skin...my teeth had been

${ }^{1}$ Related to financial risk, on March 16, 2020, Cirque du Soleil laid off 2600 employees (1200 artists and 1400 technicians) as a result of the COVID-19 outbreak. pushed up into my skull. My jaw was cut, and I had two lateral cracks in my head...both of my wrists were broken...It was centimeters from me snapping my spine. I was thrown to the ground at force because of the way the wire was rigged. The carabiner that was holding it on one side was a carabiner that was not rated for that work. It was the wrong piece of equipment... [Circus_02, woman]

I've heard of a certain apparatus...people dropping like flies...people were just getting injured left and right. They had replacements lined up so they weren't changing the apparatus. They were just changing all the people. [Circus_03, woman]

To navigate the possibility of injury, aerialists enthusiastically point to a kind of "circus luck" when describing traumatic injuries.

...it was during a rehearsal. I had asked the rigger and my coaches, I kept asking, "Is this safe?" Is this safe?... But, I think they just thought that an engineer had looked at it, but it turns out that no one had looked at it...So I asked them to tighten it, but then the rigger was training a new technical director at that point...and he dropped my lines, which wasn't normal...the next thing that I remember was a loud crack...luckily because of the cracks in my skull my brain was able to expand so I didn't suffer any brain damage, knock on wood. I was very lucky...I was thrown to the ground at force because of the way the wire was rigged...No one else was hurt even though this massive structure went flying across the gym. [Circus_02, woman]

A new team comes in and puts up the trapeze so, basically, you're using equipment that you're assuming nothing has gone wrong with it in a way that you can't know when you're taking care of your own personal belongings...basically, the shackle spontaneously hopped, 
and so there are two of them, one on each side and one broke so the board went vertical and the person who was standing on the outside fell, and I fell so she is so lucky, so lucky. I heard she hit the net, I was too busy with my own problems to see what happened with her, but, basically, one of the biggest strongest guys on her team happened to be standing where she fell and freaking caught her like this. Like a baby. She is so lucky, I mean, it's like the stars lined up...I was so lucky and she was so lucky it could have been so much worse. [Circus_19, woman]

Another aerialist thought of risk in terms of repetition. Proper technique requires the repetition of practice. When the act is not fresh and the aerialist is repeating the same movements and routine, a fall can result from a lack of focus.

An automatic pilot is a lot more dangerous than actual big tricks that you're throwing...with something small and simple I've more often fallen on a really simple trick just because I wasn't paying attention than a really hard one. [Circus_07, woman]

The possibility of injury and learning to control the body under the aerialist's extreme circumstances is part of the thrill.

The risk of injury also connects aerialism with "edgework" as the aerialist flirts with the potential of injury and losing control. Lyng (2004) describes risk-taking behavior as "edgework" or the exploration of life and death. Edgework is about performance and the fine line between being out of control and harnessing excitement in life and death contexts (Laurendeau 2006). There is an emotional element of living on the edge or being in and out of control (Kusenbach and Loseke 2013; Coetzee 2020). The thrill is experienced physically and shared with the audience. The idea of risk allows for intense pleasure.
Something about the circus that really drew me in was this element of constantly being on the edge. It is mind-blowing to people when they first see it because they don't quite comprehend how it's done... If people are asking themselves how and why at the end of a performance, then I've done my job. Being on the edge also is the element of risk, too...you're on a rope and you do a head dive straight down and your head lands inches from the floor, that to me is what circus is all about...to make people think that, wow, you might actually split your head open and then you don't...If something goes wrong, there's always a moment in the audience where people go, "Oh," they breathe in...and they wonder if everything is OK...it draws them closer to you. [Circus_04, man]

A lot of that has to do with the inherent risk attached to the industry...the thing about the circus that makes it popular is that sense of danger and sense of risk so that makes it appealing that people want to see that, however, it's much safer than the perceived risk because we're, it is calculated risk that we're participating in. We train, we're really aware of what we're doing, and we do check all of our equipment... [Circus_24, woman]

In the latter portion of this quote, the aerialist first mentions the risk, then diminishes the risk by stating it is a calculated risk that they train to surmount. This quote demonstrates the risk-taking level of the aerialist that the general public may not appreciate. The risk level of the aerialist is high enough that they continue this work even though they may have to use their financial means for rehabilitation after obtaining injuries from training or performances. One aerialist [Circus 02, woman] described an accident in which she fell 11 feet and had just enough money to eat, pay the rent, and pay for rehabilitation from severe injury. 
An injury is a threat to the aerialist's physical body, as well as their ability to express themselves creatively and emotionally. The injured body prohibits performing and causes the aerialist a temporary loss of their identity (also see Allen-Collinson 2017). The injured aerialist faces reality head-on, in that their injury pulls them away from the world of circus aerialism. Aerialists appear to view themselves as different from others, so the idea of stopping circus work can be disheartening. This notion is clear when aerialists describe "circus" people as distinct from "normal" people.

...it's very painful when you go from being a normal person to a circus artist. [Circus_02, woman]

However, as described in the next section, the process of injury and retirement can also be painful for aerialists.

\section{Injury and the Erosion of Body Capital}

While the body changes to conform to the techniques of circus aerialism, the body may plateau. When an injury forces the aerialist to discontinue training, the body will undergo another transformation to conform to the healing stages and lose the developments gained during aerialism training. The mind also transforms as it must adapt to a more sedentary lifestyle than it is accustomed to as the body recovers from injury. At the same time, the body is healing, the mind is at a grieving stage as it contemplates the work that will be undone, such as learning to handle fear.

With my own body, if I stop training, everything disappeared. I don't have calluses anymore, but if I start training tomorrow morning, I know it's going to come back in 2-3 months. [Circus_01, woman]
It's not just physical pain. It's the realization that you're going to be physically, financially, just impact in your day-to-day life...Anybody who's been training has a basic understanding of what the magnitude of their injuries are, like all of a sudden you realize that a moment ago you were training and all of a sudden it's going to be 6-8 months. [Circus_18, man]

Physical fitness does not correlate directly with injury prevention (Jones et al. 2017). In aerialism, there is an imminent sense of injury given the intense nature of aerial performances and the technical nature of aerial rigging. When aerialists deal with tendonitis and bodily breakdowns, they can see and feel their body capital disbanding.

What happened was from so much repetition certain muscles had gotten over-worked, and other muscles I wasn't working on were muscles that I needed to use, I used the strong muscles to compensate for them. So, I had built sort of these smaller muscles that were a bit weaker around the shoulder area, a lot of physical therapy. [Circus_25, woman]

As in many sports, there is a normalizing of injuries because aerialists cannot afford time away from training without losing strength and flexibility. Further, there is competitive pressure to perform. While classical ballet dancers consider injuries as devastating to their career, they also consider them a component of ballet and often prioritize the ballet show ahead of injury and pain (Turner and Wainwright 2003). Likewise, aerialists abuse their bodies by denying the need for healing so that they may continue to perform.

As an aerialist, the last thing that you want to hear is that you, for sure, are injured and that you need to stop working because you just can't afford to do that. You 
especially can't afford to pay someone to tell you to stop working... [Circus_19, woman]

Many of the circus aerialists we interviewed suffered serious injuries from work. Allen-Collinson (2005) examines the emotional aspects of athlete experience of and recovery from injury. The way athletes experience pain and injury relates to how long they participate in this activity and the goals they set. As the aerialist's body wears down, the risk of injury increases (Dickson 2018); yet, most circus aerialists lack access to organization-based physiotherapy and care. When the body becomes incapacitated, it means disruption to the aerialist's sense of the self. When the aerialist must consult the outside expert of the medical profession, it is humiliating to the aerialist who considers themselves as knowing their body better than anyone else. Throughout injury to recovery, the managing of pain involves a government of the body that returns to basic repetition and training. Sparkes and Smith (2002) consider how injured people define themselves as disabled. The respondents talk about their bodies as becoming problematic, as did several aerialists. Much like what Tulle (2008) notes about aging runners, the athletic competence of aerialists is retained, yet the body capital of the aerialist erodes.

\section{Aging Out}

It takes years to shape the aerialist body to perform death-defying feats, yet aerialism is a short-lived profession. While the body transforms to become an aerialist, it eventually reaches an end-stage due to age and injury. Toward the end of the career, pain may consume the body. Similar to retired military personnel (Williams et al. 2018), aging out of aerialism is a shock to the self and the body's familiarity with routines (also see Bieńko 2018). It is important to explore how aerialists make sense of aging and the pains that the aging body produces (Encandela 1997). The passion for their art is so strong, not even pain holds some aerialists back from performing.

As athletes, aerialists are very passionate people and especially if you're an athlete who would be what I would call in the good enough category...I'm good enough to be working, but I'm not elite. So when you fall into the good enough category, then to make up the difference between yourself and someone who is at an actual elite level, you have to make up that difference with perseverance and dedication. So for someone to tell you that you can't train or you can't do to make it happen it's, you have to be very stubborn about your persistence in your task. And you cannot have a doctor or someone telling you don't do it. [Circus_19, woman]

This next aerialist's description of performing indicates that aerialists know nothing else like the feeling of aerialism.

It is unreal when you are performing in the air, but I think, for most of the artists, it's very unreal when they are on the stage. They are in a place that they don't know anywhere else. They don't feel that way anywhere else than on stage under a spotlight. [Circus_01, woman]

This surreal description of aerialism can help one to understand the shock aerialists experience when aging out of their career and the show ends.

At the end of their aerialist journey, not only are aerialists faced with deteriorating bodies but a loss of whom they have become. At a young age, they must reinvent themselves to belong within the aerialist world. While their bodies may no longer be able to perform as they once did, their passion and drive for risk may still ensue. Some aerialists who have destroyed their bodies through their work continue 
to provide the ontological narratives of an aerialist. They even make sense of their self through aerialism, despite no longer conducting aerialist work.

I'm 30 now, but I have started to feel my mortality. Through injuries, fatigue, I can feel it where there are days where I don't feel any older, but I recognize that I'm more than my body. What I'm really doing to the organization [as a coach] is putting everything I've learned into a body of knowledge, which people can access that will live on...When I'm ready, don't reincarnate me, I don't want to be reborn, when this life's over, I want to rest. I'm going to be tired. Don't bring me back, I want to be dead. By that point, I'll have transitioned what I want, the legacies in this world into the organization, and that will live on...So I see my body as sort of that physical conduit for the stories and the ideas that have come through it. [Circus_18, man]

The aerialists are aware of how short their careers are as aerialists, and many translate their body capital to cultural and social capital after their circus careers end due to age or injury.

I often do consulting with people who are just starting in the circus...you can either be smart about it and learn the dynamics of the business or you can starve, or you can supplement it with getting what's called a real job...I'm my own agent, and the Internet makes it incredibly easy, so I know how to negotiate contracts... So if you embark upon the process of doing it all yourself, then you get the alternate skills of knowing how to become a businessperson, as well. [Circus_05, man]

Aerialists can experience a sense of devastation when told they ought to stop due to injury or age. Wainwright and Turner (2006) argue that social constructionist arguments in the sociology of the body literature fail to consider the materiality of the body and aging. Drawing from ballet dancers' stories about their craft, Wainwright and Turner argue that dancers' body capital declines with injury and aging. The case is similar for aerialists. Work destroys bodies, and if work does not provide opportunities for the body to heal due to the contractual nature of the work, the body of the worker will break down. Some aerialists develop marketing and business skills and work in the circus industry administration. Other aerialists might find themselves with opportunities such as coaching, choreography, and set design.

\section{Discussion and Conclusion}

The body is at the core of the existence of the aerialist and their craft. We examined how aerialists talk about their bodies work and how work wears down their bodies, eventually making it impossible to retain and mobilize the body capital to continue being an aerialist. Allen-Collinson, Crust, and Swann (2019) focus on the senses and tacit knowledge of high-altitude mountaineers and how this connects to their bodily practices. Like high-altitude mountaineers, aerialists sense how things should be or when things are going awry with their rigs and with their bodies (also see O'Connor 2007). Aerialists demonstrate this sense in their routines of learning to tolerate pain, adjusting their bodies with the equipment to avoid injury, and using adrenaline to perform through injury. Knowing their time as circus artists is short-lived, they push their bodies beyond pain and risk boundaries. Shedding light on how aerialists make meaning out of pain (Bendelow and Williams 1995; Turner and Wainwright 2003), we have shown how aerialists endure incredible amounts of pain, as well as gruesome injuries, and interpret these happenings using frames such as circus luck. Body callusing (Spencer 2009) and skilled pain tolerance give way to injury and aging. Aerialists may still stay involved like endurance runners run for run- 
ning's sake (Tulle 2007). Nevertheless, the experience is not the same since the disrupted body (Allen-Collinson 2017) becomes a challenge to overcome instead of a tool to use in high-level performance.

Our work resonates with Wainwright and Turner's (2006) exploration of ballet dancers and aging since we focus on the lived experience of embodiment and trace the rise and fall of body capital with aerialists over time. Aches, pains, and body battles are common. When people age in ballet, their physical capital declines. They must begin to draw on cultural capital to make advances in the field. A similar dynamic or cycle occurs in aerialism. Aerialists are putting themselves at risk of injury with every maneuver, and their accumulation of body capital leads to risk, injury, and even inequality (Shilling 1991; Stephens 2015) in ways we have hinted at, but that deserve more attention in future research. Social and cultural capital becomes key for aerialists staying in the industry as teachers or administrators.

\section{References}

Albrecht, Ernest. 1995. The New American Circus. Gainesville, FL: University of Press of Florida.

Allen-Collinson, Jacquelyn. 2005. “Emotions, Interaction and the Injured Sporting Body." International Review for the Sociology of Sport 40(2):221-240.

Allen-Collinson, Jacquelyn. 2017. “Injured, Pained and Disrupted Bodies." Pp. 267-276 in Routledge Handbook of Physical Cultural Studies, edited by M. Silk, D. Andrews, and H. Thorpe. London: Routledge.

Allen-Collinson, Jacquelyn and John Hockey. 2011. “Feeling the Way: Notes toward a Haptic Phenomenology of Distance Running and Scuba Diving." International Review for the Sociology of Sport 46(3):330-345.
Circus organizations are now big enterprises and businesses (Beadle and Könyöt 2006; Parker 2011), and there is a sense in which circus organizations are harvesting the body capital of aerialists. We have examined body callusing and body capital in an artistic, creative, but nonetheless demanding form of physical work. Circus aerialists work to build body capital, though it dissipates over time due to stress on the body, age, and injuries. Aerialists must artfully negotiate the decline of their bodily capital and the pains of aging while, at the same time, trying to maintain the physical capital needed to perform. In the end, despite heaps of tacit and sensual knowledge, the aerialist has little body capital left. At best, they can translate this body capital into social and cultural capital. To the outside observer, losing one's physical capital at the end of an aerialist career must be better than losing one's life after being hurled from a faulty rig. And yet, given the centrality of the body to the work of aerialists, exiting the stage for the last time entails a deep sense of loss, a pain that many aerialists can never entirely accept.

Allen-Collinson, Jacquelyn, Lee Crust, and Christian Swann. 2018. “'Endurance Work': Embodiment and the Mind-Body Nexus in the Physical Culture of High-Altitude Mountaineering." Sociology 52(6):1324-1341.

Allen-Collinson, Jacquelyn, Lee Crust, and Christian Swann. 2019. "Embodiment in High-Altitude Mountaineering: Sensing and Working with the Weather." Body \& Society 25(1):90-115.

Austin, D. Mark. 2009. "Ritual and Boundary Distinction in a Recreational Community: A Case Study of Motorcycle Rallies and Riders." Qualitative Sociology Review 5(2):70-93.

Beadle, Ron and David Könyöt. 2006. "The Man in the Red Coat-Management in the Circus." Culture and Organization 12(2):127-137. 
Bendelow, Gillian and Simon Williams. 1995. "Transcending the Dualisms: Towards a Sociology of Pain." Sociology of Health and Illness 17(2):139-165.

Berzon, Alexandra and Mark Maremont. 2015. "Injuries Put Safety in Spotlight at Cirque du Soleil." The Wall Street Journal, April 22. Retrieved July 23, 2021 (https://www.wsj. com/articles/injuries-put-safety-in-spotlight-at-cirque-dusoleil-1429723558).

Bieńko, Mariola. 2018. "The Body as a Private and Social Space. The Margins of Research Regarding Old Age and Gender." Qualitative Sociology Review 14(2):52-77.

Bourdieu, Pierre. 1978. "Sport and Social Class." Social Science Information 17(6):819-840.

Byczkowska-Owczarek, Dominika. 2020. "Body and Social Interaction: The Case of Dance. Symbolic Interactionist Perspective." Qualitative Sociology Review 16(4):164-179.

Carmeli, Yoram. 1996. "Marginal Body and Bourgeois Cosmology: the British Acrobat in Reference to Sport." International Journal of Comparative Sociology 37(3-4):252-274.

Carmeli, Yoram. 2003. "Lion on Display: Culture, Nature, and Totality in a Circus Performance." Poetics Today 24(1):65-90.

Carmeli, Yoram. 2007. "Traveling and Family in the 1970s British Circus." Semiotica 167(1/4):369-385.

Chapman, Gwen. 1997. “Making Weight: Lightweight Rowing, Technologies of Power, and Technologies of the Self." Sociology of Sport Journal 14(3):205-223.

Coetzee, Jan. 2020. “Narrating Emotions: Towards Deeper Understanding." Qualitative Sociology Review 16(1):12-27.

Corbin, Juliet and Janice Morse. 2003. "Reciprocity and Risks when Dealing with Sensitive Topics." Qualitative Inquiry 9(3):335-354.

Corteen, Karen. 2019. "Regulating the Harmful, Injurious and Risky Business of Professional Wrestling." Pp. 167-178 in The Suffering Body in Sport (Research in the Sociology of Sport, Volume 12), edited by K. Young. London: Emerald.

Crossley, Nick. 2005. "Mapping Reflexive Body Techniques: On Body Modification and Maintenance." Body \& Society 11(1):1-35.
Davis, Janet. 2002. The Circus Age: Culture \& Society under the American Big Top. Durham, NC: University of North Carolina Press.

Dickson, Tracey. 2018. "Snowsport Experience, Expertise, Lower Limb Injury and Somatosensory Ability." Journal of Science and Medicine in Sport 22:S17-S21.

Easto, Patrick and Marcello Truzzi. 1973. "Towards an Ethnography of the Carnival Social System." Journal of Popular Culture 6(3):550-566.

Encandela, John A. 1997. "Social Construction of Pain and Aging: Individual Artfulness within Interpretive Structures." Symbolic Interaction 20(3):251-273.

Frew, Matt and David McGillivray. 2005. "Health Clubs and Body Politics: Aesthetics and the Quest for Physical Capital." Leisure Studies 24(2):161-175.

Giardina, Michael and Michele Donnelly. 2017. “Introduction: Physical Culture, Ethnography, and the Body." Pp. 1-22 in Physical Culture, Ethnography and the Body, edited by M. D. Giardina and M. Donnelly. London: Routledge.

Hockey, John and Jacquelyn Allen-Collinson. 2017. “Running a Temperature: Sociological-Phenomenological Perspectives on Distance Running, Thermoception and 'Temperature Work."' Pp. 42-62 in Seeking the Senses in Physical Cultures: Sensual Scholarship in Action, edited by A. Sparkes. London: Routledge.

Hutson, David. 2013. "'Your Body Is Your Business Card': Bodily Capital and Health Authority in the Fitness Industry." Social Science \& Medicine 90:63-71.

Ingold, Tim. 2000. The Perception of the Environment: Essays on Livelihood, Dwelling and Skill. London: Routledge.

Jones, Bruce et al. 2017. "Impact of Physical Fitness and Body Composition on Injury Risk among Active Young Adults: A Study of Army Trainees." Journal of Science and Medicine in Sport 20:S17-S22.

Kusenbach, Margarethe and Donileen Loseke. 2013. “Bringing the Social Back In: Some Suggestions for the Qualitative Study of Emotions." Qualitative Sociology Review 9(2):20-38.

Laurendeau, Jason. 2006. "'He Didn't Go in Doing a Skydive': Sustaining the Illusion of Control in an Edgework Activity." Sociological Perspectives 49(4):583-605. 
Little, Kenneth. 1995. "Talking Circus, Not Culture: The Politics of Identity in European Circus Discourse." Qualitative Inquiry 1(3):346-359.

Lyng, Stephen. 2004. "Crime, Edgework and Corporeal Transaction." Theoretical Criminology 8(3):359-375.

Nespor, Jan. 2000. "Anonymity and Place in Qualitative Inquiry." Qualitative Inquiry 6(4):546-569.

O'Connor, Erin. 2007. "The Centripetal Force of Expression: Drawing Embodied Histories into Glassblowing." Qualitative Sociology Review 3(3):113-134.

Oleschuk, Merin and Helen Vallianatos. 2019. "Body Talk and Boundary Work among Arab Canadian Immigrant Women." Qualitative Sociology 42(4):587-614.

Parker, Martin. 2011. “Organizing the Circus: The Engineering of Miracles." Organization Studies 32(4):555-569.

Rafalovich, Adam. 2016. "Pain is the Club: Identity and Membership in the Natural Childbirth Community." Qualitative Sociology Review 12(3):100-116.

Rantisi, Norma and Deborah Leslie. 2015. "Circus in Action: Exploring the Role of a Translation Zone in the Cirque du Soleil's Creative Practices." Economic Geography 91(2):147-164.

Rau, Asta. 2020. "Dealing with Feeling: Emotion, Affect, and the Qualitative Research Encounter." Qualitative Sociology Review 16(1):94-108.

Roderick, Martin, Andy Smith, and Paul Potrac. 2017. “The Sociology of Sports Work, Emotions and Mental Health: Scoping the Field and Future Directions." Sociology of Sport Journal 34(2):99-107.

Shilling, Chris. 1991. "Educating the Body: Physical Capital and the Production of Social Inequalities." Sociology 25(4):653672 .

Shilling, Chris. 2004. "Physical Capital and Situated Action: A New Direction for Corporeal Sociology." British Journal of Sociology of Education 25(4):473-487.

Shilling, Chris. 2005. The Body in Culture, Technology and Society. London: Sage.

Shilling, Chris. 2017. "Physical Capital and Situated Action: A New Direction for Corporeal Sociology." Pp. 62-85 in Physical
Culture, Ethnography and the Body, edited by M. D. Giardina and M. Donnelly. London: Routledge.

Sparkes, Andrew and Brett Smith. 2002. "Sport, Spinal Cord Injury, Embodied Masculinities, and the Dilemmas of Narrative Identity." Men and Masculinities 4(3):258-285.

Spencer, Dale. 2009. “Habit(us), Body Techniques and Body Callusing: An Ethnography of Mixed Martial Arts." Body E Society 15(4):119-143.

Stephens, Lindsay. 2015. “The Economic Lives of Circus 'Artists': Canadian Circus Performers and the New Economy." Canadian Journal of Communication 40(2):243-260.

Stephens, Lindsay. 2019. "Becoming Acrobat, Becoming Academic: An Affective, Autoethnographic Inquiry into Collective Practices of Knowing and Becoming." Cultural Studies $\leftrightarrow$ Critical Methodologies 19(4):264-274.

Stoddart, Helen. 2000. Rings of Desire: Circus History and Representation. Manchester: Manchester University Press.

Tait, Peta. 2005. Circus Bodies: Cultural Identity in Aerial Performance. London: Routledge.

Tracy, Sarah. 2010. “Qualitative Quality: Eight ‘Big Tent' Criteria for Excellent Qualitative Research.” Qualitative Inquiry 16(10):837-851.

Truzzi, Marcello. 1968. "The Decline of the American Circus: The Shrinkage of an Institution." Pp. 314-322 in Sociology and Everyday Life, edited by M. Truzzi. New Jersey, NY: Prentice-Hall.

Tulle, Emmanuelle. 2007. "Running to Run: Embodiment, Structure and Agency amongst Veteran Elite Runners." Sociology 41(2):329-346.

Tulle, Emmanuelle. 2008. "The Ageing Body and the Ontology of Ageing: Athletic Competence in Later Life." Body $\mathcal{E}$ Society 14(3):1-19.

Turner, Bryan S. 1982. “The Government of the Body: Medical Regimens and the Rationalization of Diet." British Journal of Sociology 33(2):254-269.

Turner, Bryan S. and Steven P. Wainwright. 2003. "Corps de Ballet: The Case of Injured Ballet Dancer." Sociology of Health and Illness 25(4):269-288.

Tynan, Ruby and Nollaig McEvilly. 2017. “'No Pain, No Gain': Former Elite Female Gymnasts' Engagements with Pain and Injury Discourses." Qualitative Research in Sport, Exercise and Health 9(4):469-484. 
Van Lenning, Alkeline. 2004. "The Body as Crowbar: Transcending or Stretching Sex?" Feminist Theory 5(1):25-47.

Vannini, Phillip and Aaron McCright. 2004. "To Die For: The Social Semiotic Seductive Power of the Tanned Body." Symbolic Interaction 27(3):309-332.

Wacquant, Loïc. 1995. "Pugs at Work: Bodily Capital and Bodily Labour among Professional Boxers." Body $\mathcal{E}$ Society1(1):65-93.

Wacquant, Loïc. 2004. Body E Soul: Notebooks of an Apprentice Boxer. Oxford: Oxford University Press.
Wainwright, Steven P. and Bryan S. Turner. 2006. "'Just Crumbling to Bits?' An Exploration of the Body, Ageing, Injury and Career in Classical Ballet Dancers." Sociology 40(2):237-255.

Williams, Rachel et al. 2018. "'You're Just Chopped Off at the End': Retired Servicemen's Identity Work Struggles in the Military to Civilian Transition." Sociological Research Online 23(4):812-829.

Wolkowitz, Carol. 2002. "The Social Relations of Body Work." Work, Employment and Society 16(3):497-510.

Wolkowitz, Carol. 2006. Bodies at Work. London: Sage.

\section{Citation}

Walby, Kevin and Shawn Stuart. 2021. "You Have to Accept the Pain': Body Callusing and Body Capital in Circus Aerialism." Qualitative Sociology Review 17(4):6-23. Retrieved Month, Year (http://www.qualitativesociologyreview.org/ENG/archive_eng. php). DOI: https://doi.org/10.18778/1733-8077.17.4.01 